Article

\title{
Analysis of Solar Energy Utilization Effect of Air-Based Photovoltaic/Thermal System
}

\author{
Youngjin Choi ${ }^{1}$ and Hyun Bae Kim ${ }^{2, *}$ \\ 1 Department of Architectural Engineering, Kyonggi University, Suwon 16227, Korea; yjchoi@kyonggi.ac.kr \\ 2 Graduate School of Agricultural and Life Sciences, The University of Tokyo, Tokyo 113-8657, Japan \\ * Correspondence: kim.hyunbae@mail.u-tokyo.ac.jp
}

check for updates

Citation: Choi, Y.; Kim, H.B.

Analysis of Solar Energy Utilization Effect of Air-Based Photovoltaic/ Thermal System. Energies 2021, 14, 8586. https://doi.org/10.3390/ en14248586

Academic Editor: Alfredo Guardo Zabaleta

Received: 13 November 2021 Accepted: 14 December 2021 Published: 20 December 2021

Publisher's Note: MDPI stays neutral with regard to jurisdictional claims in published maps and institutional affiliations.

Copyright: (c) 2021 by the authors. Licensee MDPI, Basel, Switzerland. This article is an open access article distributed under the terms and conditions of the Creative Commons Attribution (CC BY) license (https:/ / creativecommons.org/licenses/by/ $4.0 /)$.

\begin{abstract}
Recently, the use of new and renewable energy sources to reduce carbon dioxide emissions and minimize global warming has attracted attention. Among the different renewable energy sources, solar energy is utilized for energy reduction in buildings because of its ease of use and excellent maintenance and repair. In this study, an air-based photovoltaic/thermal (PVT) system that improves solar energy utilization was developed, and its performance was experimentally compared with that of the existing photovoltaic (PV) system. The PVT system could increase the amount of generated power by decreasing the panel temperature raised by the air passing through the lower part of the panel. Moreover, it was possible to use the high-temperature air collected from the panel for heating or hot-water supply in the building. Based on the experimental results obtained for the PV and PVT panels subjected to the same weather conditions, the power generation efficiency of the PVT panel through which air was passed increased by approximately $10.1 \%$ compared to that of the PV panel. In addition, a heat collection efficiency of approximately $46.6 \%$ was generated by the temperature increase of the air passing through the PVT panel.
\end{abstract}

Keywords: solar energy; photovoltaic/thermal system; energy utilization efficiency

\section{Introduction}

Recently, interest in the use of new and renewable energy has increased, owing to global warming caused by the utilization of fossil fuels and the dangers of nuclear power generation. In addition, since the United Nations Framework Convention on Climate Change in 1992, efforts to curb the increase in global temperature are in progress. Accordingly, the Intergovernmental Panel on Climate Change proposed reducing carbon dioxide emissions by at least $45 \%$ by 2030 compared to 2010 emissions and achieving carbon neutrality by 2050 to limit the increase in the global average temperature to within $1.5^{\circ} \mathrm{C}$ by 2100. Countries worldwide have voluntarily presented their greenhouse gas reduction goals since 2016 and developed long-term low greenhouse gas emission development strategies and national greenhouse gas reduction goals (agreed to submit a Nationally Determined Contribution). Many countries are setting their paths toward carbon neutrality by developing strategies suitable for each sector, such as the energy supply and industry, transportation, and building sectors. In particular, efforts are made to minimize greenhouse gas emissions by utilizing new and renewable energy such as solar collector [1], evacuated tube collector [2,3], double slope collector [4], air-based solar system [5,6], application $[7,8]$ and so on. Among the different renewable sources of energy, solar energy is actively investigated because of its abundance, ease of installation, and simple maintenance. Martinopoulos et al. investigated the actual use of solar energy and its effects, and indicated the need for solar energy policy and activation at the national level [9]. In addition, many studies are being conducted to improve building energy performance through the utilization [10] and optimization [11] of a building-integrated photovoltaic system.

Despite the several advantages of solar power generation systems, such as diverse applicability, power generation is possible only during the daytime, and expensive batteries 
are required to store the remaining power. Consequently, the construction field distribution is delayed. Interest in and research on photovoltaic/thermal (PVT) systems capable of generating electricity using solar light and collecting heat using solar heat simultaneously are increasing [12]. The PVT system controls the decrease in power generation efficiency, owing to the temperature rise of the panel by enabling the flow of the liquid or gas to the back of the solar panel. In addition, it can be used for hot water supply or heating in a building by utilizing a liquid or gas with an increased temperature [13].

Zarei et al. used R600a and R290 refrigerants as replacements of R134a refrigerants to increase the photovoltaic (PV) efficiency and decrease global warming. The temperature of the water passing through the panel increased by approximately $9.14^{\circ} \mathrm{C}$, and the efficiency of the PVT system improved from $66.7 \%$ to $75.8 \%$ [14]. Nazri et al. evaluated an air-based PVT system and observed that the utilization effect of the maximum solar energy was possible up to $80.3 \%$; moreover, the PVT system exhibited higher potential than the existing PV system [15]. In another study on an air-based PVT system, Ozakin et al. performed simulations and found that the panel surface temperature decreased by approximately $10-15^{\circ} \mathrm{C}$ when air passed under the panel; in addition, the efficiency increased by approximately $15 \%$, owing to an increase in wind speed [16]. Wajs et al. decreased the PV surface temperature by up to $6.3^{\circ} \mathrm{C}$ by cooling the air between the PV panel and the roof, increasing the power generation and demonstrating the applicability of the target system [17]. Singh et al. reported that the solar heat could be increased by approximately 1.4 times because of the parallel configuration of the PVT system, and it was more effective than the serial configuration in economic terms [18]. In the study conducted by Abdullah et al., the panel surface temperature decreased by approximately $5-9{ }^{\circ} \mathrm{C}$ compared to the conventional PV in a liquid PVT system, increasing the power generation efficiency [19]. Vittorini et al. improved the power generation efficiency by approximately $33 \%$ compared to the existing PV by supplying 2 L cooling water per minute [20]. Sakellariou et al. developed a method for applying the PVT system and demonstrated the possibility of using it as thermal energy while increasing the power generation efficiency, owing to the liquid passage. In addition, the higher the inlet temperature of the PVT, the lower the power generation efficiency, and the amount of power generated significantly changed with the inclination of the PVT panel [21]. Brottier et al. analyzed the thermal performance of domestic hot-water facilities using 28 PVTs in Western Europe. The PVT system was more effective than the PV system for preheating domestic hot water, and there was less risk of overheating based on the highest temperature [22].

In addition, several studies on the application of the PVT system for minimizing energy consumption in buildings have been conducted. Hengel et al. reviewed a method for increasing the system efficiency by linking the PVT system and the heat pump, but further research on the appropriate point to achieve the break-even point was recommended for reasons such as high initial investment costs [23]. AlbaRamos et al. concluded that the system performance could be improved by combining a liquid PVT system and a heat pump, reducing the power consumed for cooling [24]. Calise et al. reviewed methods for maximizing the utilization of the PVT system through simulations. They reported that the summer utilization plan by solar heating and cooling and the relationship with the domestic hot water demand should be reviewed [25]. Fayaz et al. reviewed the use of a phase change material (PCM) in PVT systems and concluded that the cooling effect increased, owing to the application of the PCM; consequently, the power generation efficiency increased [26]. Reddy Penaka et al. reviewed measures to evaluate the economic feasibility of applying PVT based on country-specific climatic conditions, energy consumption and energy cost [27].

As described above, studies on the applicability of the PVT system and utilization methods have been conducted. However, the performance comparison through experiments on PV and PVT under the same conditions and the applicability of the air-based PVT system have not been investigated extensively. Therefore, in this study, the performances 
of PV and air-based PVT systems exposed to the same weather conditions were measured, and the results were compared to review the utilization plan of the air-based PVT system.

\section{Materials and Methods}

Measurements were performed on the rooftop of 7 lecture buildings in Kyonggi University (latitude: $37.30^{\circ}$, longitude: $127.04^{\circ}$ ) in Suwon-si, Gyeonggi-do, Korea. In the case of PV panels, since they are generally installed directly on the roof surface, it is assumed that the insulation of the roof surface is in direct contact with the panel, so that there is no air layer under the panel. In addition, in order to reproduce the fact that heat cannot be discharged to the lower part of the panel due to the insulation installed on the roof surface, an insulation panel was installed in the bottom part of the panel in the experiment. In the case of the PVT panel, the air was passed through the lower part of the existing PV panel (4 passages of $400 \times 50 \mathrm{~mm}$ ), and an increase in power was generated with decreasing temperature of the solar panel. The heat collection effect caused by the increased air temperature passing through the PV panel was evaluated. The changes in temperature and power generation under the same conditions were compared by installing the existing PV panel and the PVT panel (the subject of this study) side by side. The target panel faced southward and was installed at an angle of $30^{\circ}$. In addition, in order to measure the amount of insolation reaching the panel, a pyrometer was installed on the same $30^{\circ}$ inclined surface as the panel. All the target panels had the same area of $1.52 \mathrm{~m}^{2}$ $(1600 \times 950 \mathrm{~mm})$. A conceptual diagram of the panel used for the experiments is shown in Figure 1. The panel inlet temperature, upper and lower surface temperatures, and panel outlet temperature were measured to assess the temperature change of the upper and lower parts of the panel caused by air passing through the lower part of the panel. The solar irradiance, current, and voltage were measured to compare the generated power and power generation efficiency. The current-voltage (I-V) curves of the target PV panel, which present the possible combinations of current and voltage output of a photovoltaic panel, are shown in Figure 2. The maximum voltage during measurement was $35.8 \mathrm{~V}$. Therefore, as shown in Figure 2, the current value during power generation does not change significantly, and it is judged that a relatively stable result can be obtained in this experiment. The measurement instruments and items used in this study are listed in Tables 1 and 2, respectively. The measurements were performed in $1 \mathrm{~s}$ intervals, and the average results for 10 min were determined, considering the fluctuations attributed to external conditions.

B

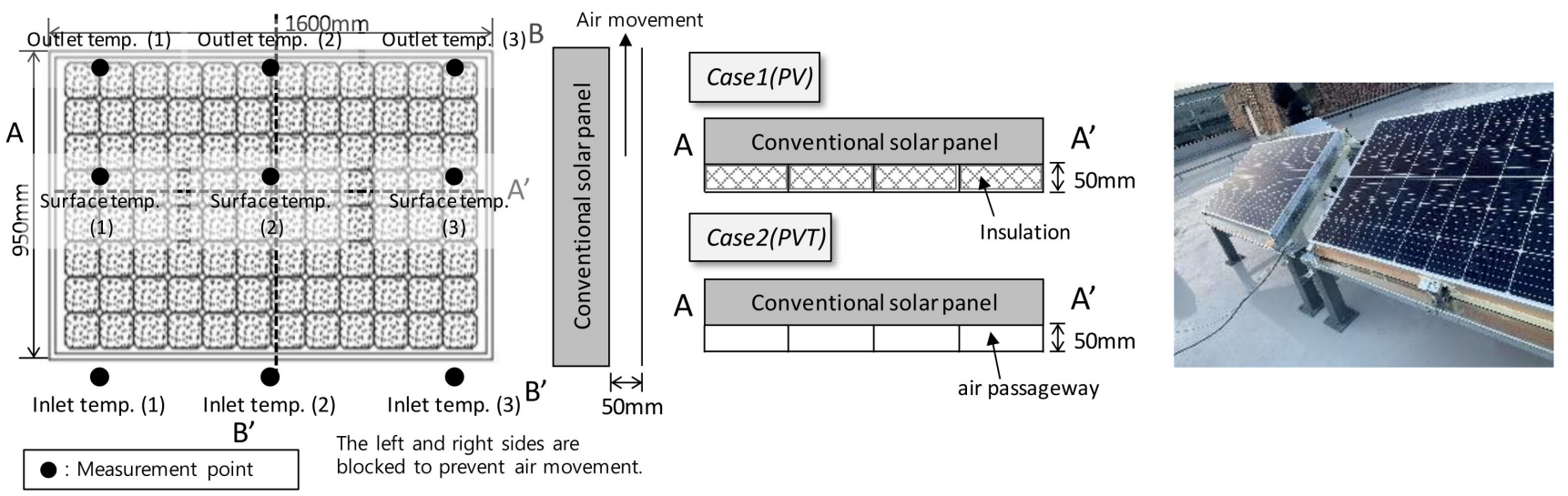

Figure 1. Schematic of experimental setup. 


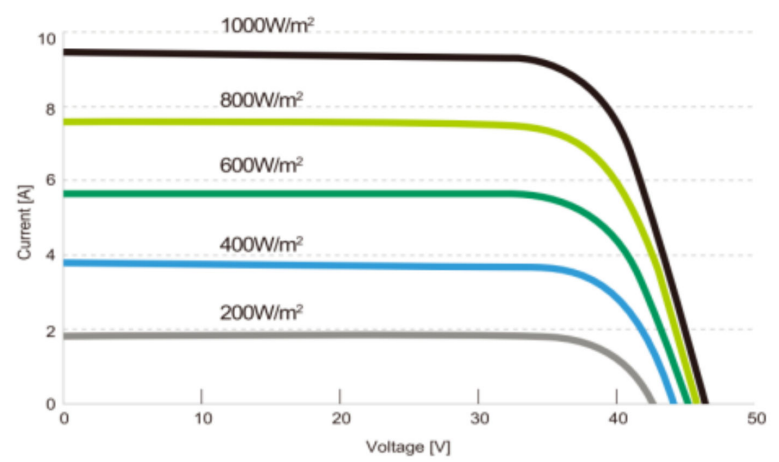

Figure 2. I-V curves of the target panel.

Table 1. Equipment specification.

\begin{tabular}{ccc}
\hline Items & Instrument & Specification \\
\hline Temperature & Thermal couple T-type & $\begin{array}{c}\text { Range: }-200-250{ }^{\circ} \mathrm{C}, \\
\text { Accuracy: } \pm 0.5^{\circ} \mathrm{C}, \text { Resolution: } 0.1^{\circ} \mathrm{C}\end{array}$ \\
\hline Solar radiation & EKO MS-40 pyranometer & Range: $0-2000 \mathrm{~W} / \mathrm{m}^{2}, \mathrm{Accuracy}: \pm 0.2 \%$ \\
\hline Electric energy & SSO 9060:2018 Class C (second class) & $10 \mathrm{~A} / 50 \mathrm{mV}$ shunt \\
\hline Wind speed & Solar volt $/$ Current unit & Range: $0-30 \mathrm{~m} / \mathrm{s}$, Accuracy: $\pm 0.1-0.3 \mathrm{~m} / \mathrm{s}$ \\
\hline Data logger & Testo 405i hot-wire anemometer & Temperature resolution: $0.01{ }^{\circ} \mathrm{C}$, \\
Voltage resolution: $500 \mathrm{nV}$
\end{tabular}

Table 2. Measurement items.

\begin{tabular}{cccc}
\hline Number & Item & Number & Item \\
\hline 1 & Outside temperature & 15 & PVT lower air temperature \\
\hline 2 & PVT air inlet temperature 1 & 16 & PV upper air temperature \\
\hline 3 & PVT air inlet temperature 2 & 17 & PV upper-surface temperature 1 \\
\hline 4 & PVT air inlet temperature 3 & 18 & PV upper-surface temperature 2 \\
\hline 5 & PVT upper-air temperature & 19 & PV upper-surface temperature 3 \\
\hline 6 & PVT upper-surface temperature 1 & PV lower-surface temperature 1 \\
\hline 7 & PVT upper-surface temperature 2 & PV lower-surface temperature 2 \\
\hline 8 & PVT upper-surface temperature 3 & PV lower-surface temperature 3 \\
\hline 9 & PVT lower-surface temperature 1 & 22 & PV lower-air temperature \\
\hline 10 & PVT lower-surface temperature 2 & 23 & Pyranometer \\
\hline 11 & PVT lower-surface temperature 3 & 24 & PVT current \\
\hline 12 & PVT air outlet temperature 1 & 25 & PVT voltage \\
\hline 13 & PVT air outlet temperature 2 & 26 & PV current \\
\hline 14 & PVT air outlet temperature 3 & 27 & PV voltage \\
\hline
\end{tabular}

\section{Measurement Results}

\subsection{Comparison of Temperature Results}

The tests were conducted for three days, 16-18 August 2021. The insolation of the panel slope for the three days were 4743, 5066, and $4020 \mathrm{Wh}$ on the first, second, and third days, respectively, with an average of approximately $4610 \mathrm{Wh}$. The minimum and maximum outdoor temperatures were 18.8 and $35.5^{\circ} \mathrm{C}$, respectively. Figure 3 shows the 
insolation and outdoor temperature during the target period. The inlet temperature of the PVT panel was at most $2.2^{\circ} \mathrm{C}$ higher than the outside temperature, and the average for the heat collection period was $0.7^{\circ} \mathrm{C}$ higher. This difference was attributed to the radiant heat generated by the temperature rise of the panel, and no significant difference with the outside temperature was observed. Figure 4 shows the inlet temperature (three points) of the PVT panel. The measurement point of the inlet temperature was set to check whether the temperature difference between the center and both ends of the panel occurred due to the influence of airflow. The average temperature of the three points according to the inlet location showed the same temperature distribution as $26.5^{\circ} \mathrm{C}$ at the point (1), $26.2^{\circ} \mathrm{C}$ at the point (2), and $26.2^{\circ} \mathrm{C}$ at the point (3). Therefore, it was found that the temperature difference due to the external influence and airflow according to the inlet location was not large. In this study, assuming that the horizontal temperature distribution and airflow inside the panel are constant, the panel performance is compared and reviewed by the simple average of the measurement point values. In addition, the inlet temperature is about 0.1 to $0.4{ }^{\circ} \mathrm{C}$ higher than the outside air temperature of $26.1^{\circ} \mathrm{C}$, so it is judged that the outside air directly flows into the panel.

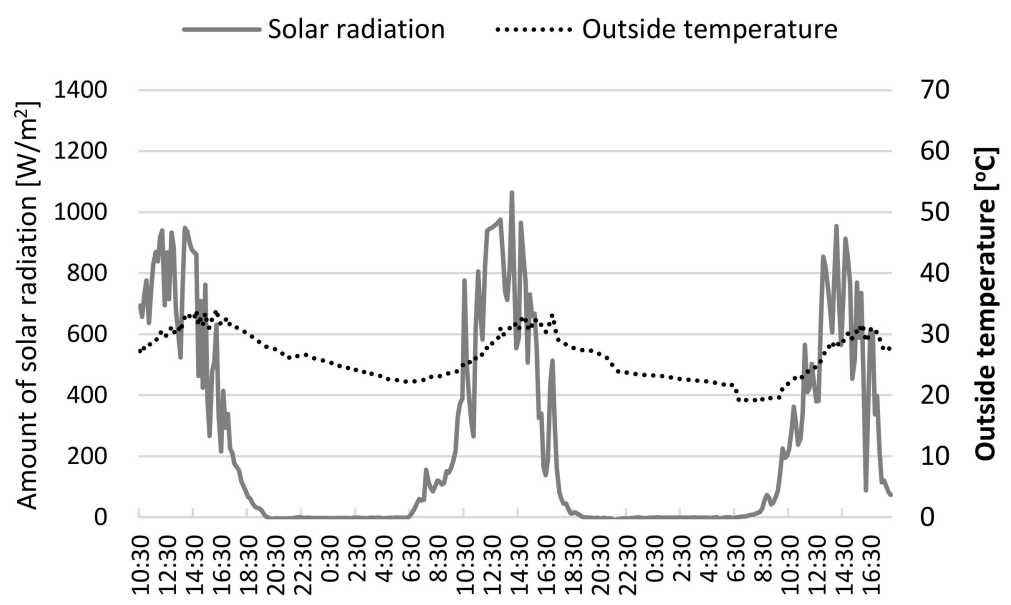

Figure 3. Solar radiation and outside temperature.

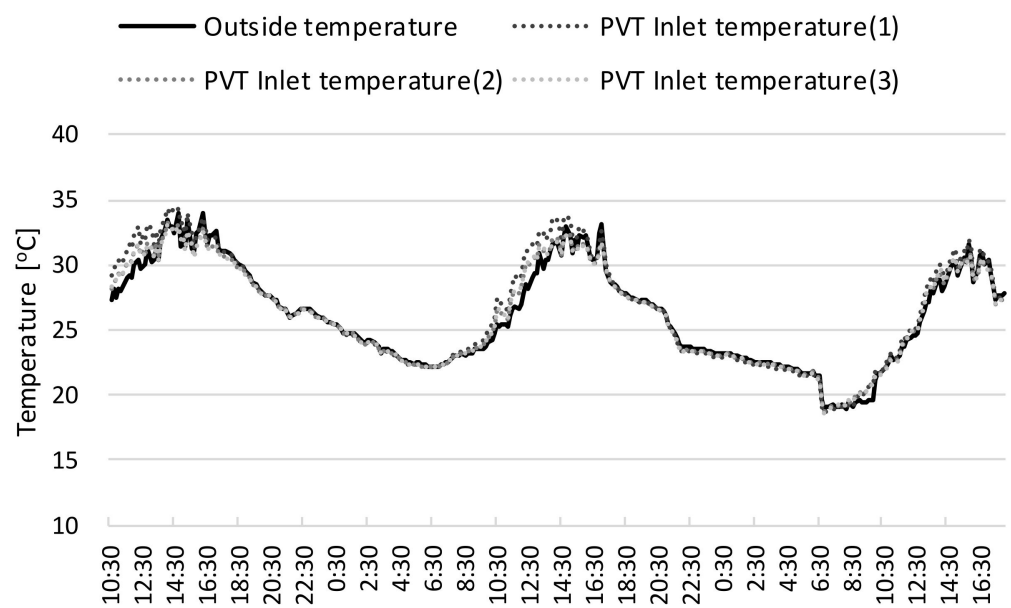

Figure 4. Inlet temperatures of the photovoltaic/thermal (PVT) panel.

For the PVT panel, which allowed air to pass through its lower part, the temperature at the top of the panel decreased by up to $10.7^{\circ} \mathrm{C}$ compared to that of the conventional $\mathrm{PV}$, and the average temperature decreased by approximately $3.0^{\circ} \mathrm{C}$ within the period (Figure 5). For the lower part of the panel (Figure 6), the temperature variation was relatively insignificant, with a maximum temperature decrease of $1.8^{\circ} \mathrm{C}$ and an average of $0.5^{\circ} \mathrm{C}$. 


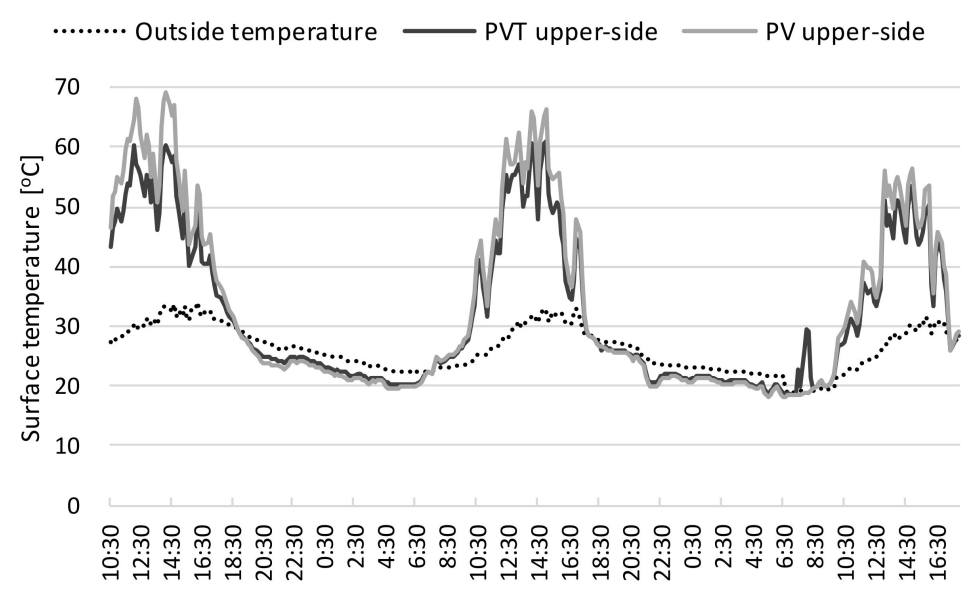

Figure 5. Upper-surface temperatures of the panels.

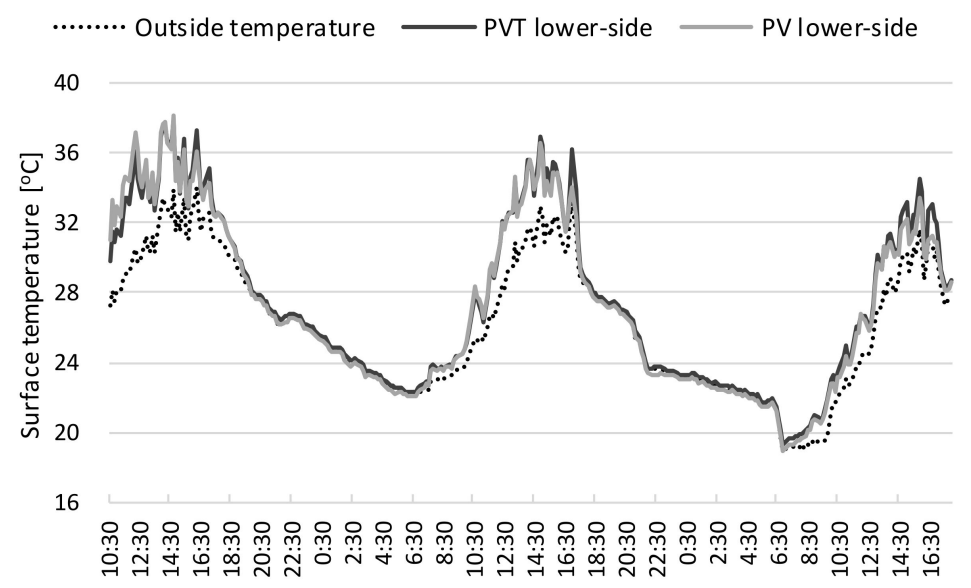

Figure 6. Lower-surface temperatures of the panels.

The temperature of the air passing through the PVT panel increased via heat exchange with the panel, whose temperature was increased by solar radiation. The air passing through the panel overheated by solar radiation had a maximum temperature increase of $6.7^{\circ} \mathrm{C}$ and an average temperature increase of $3.3^{\circ} \mathrm{C}$ (Figure 7). This increase in air temperature was highly correlated with insolation. As the amount of insolation increased, the exit temperature increased significantly (Figure 8). These results can be used for designing a PVT suitable for the target building.

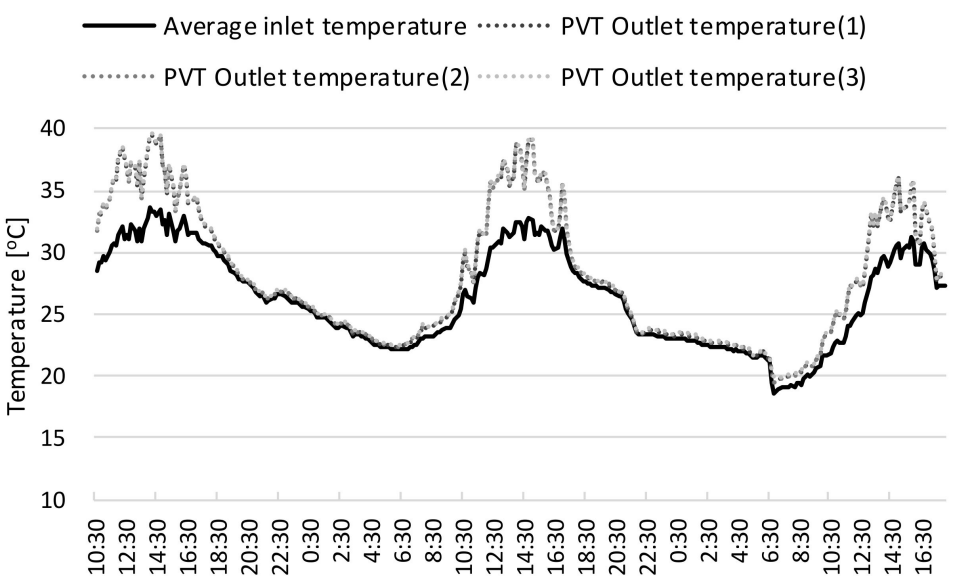

Figure 7. Outlet temperatures of the PVT panel. 


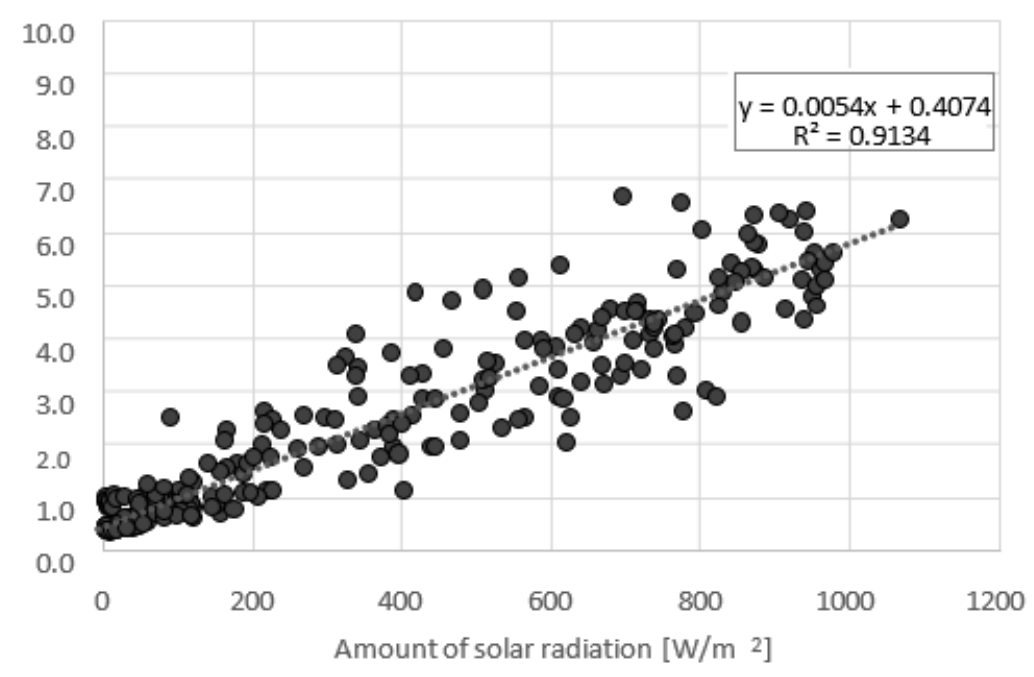

Figure 8. Relationship between insolation and outlet temperature rise.

Figure 9 shows the heat collecting effect caused by an increase in the air temperature passing through the target PVT panel. The air volume generated by the fan used in this experiment was $4.10 \mathrm{~m}^{3} / \mathrm{min}$ (diameter of $9 \mathrm{~cm}$, average wind speed of $10.74 \mathrm{~m} / \mathrm{s}$ ). The amount of collected heat was calculated by the temperature difference between the inlet and outlet of the panel, the air volume, and the specific heat of the air. The maximum amount of collected heat was $645.3 \mathrm{~W}$, and the average amount of collected heat was $261.1 \mathrm{~W}$ for the heat collection period. By passing air through the lower part of the PV panel, it is possible to not only increase the power generation amount attributed to decreased surface temperature but also collect significant thermal energy.

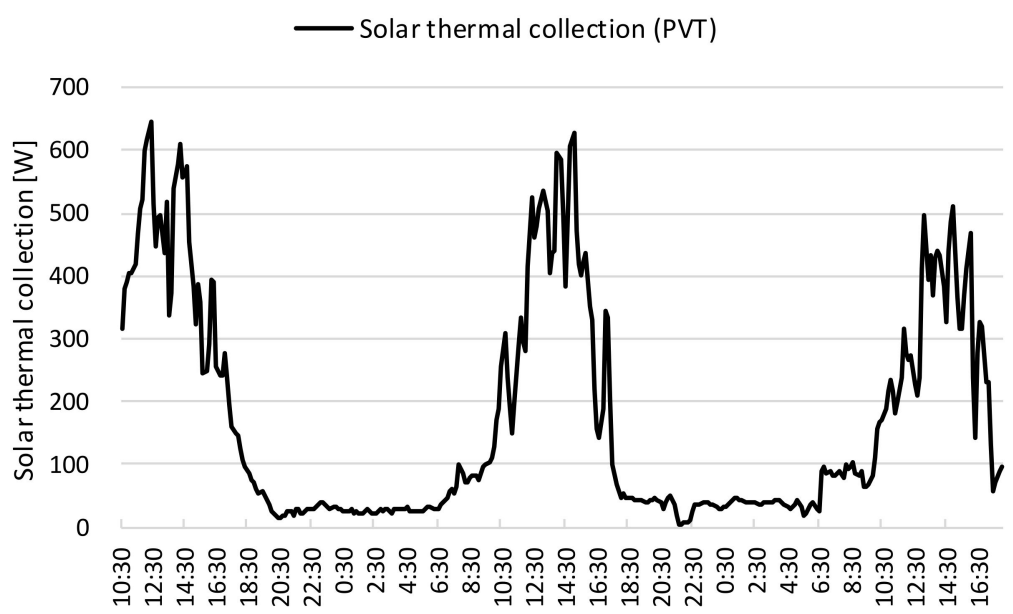

Figure 9. Heat collection by the PVT panel.

\subsection{Comparison of Power Generation Change}

The power generated by the PV and PVT panels were compared to examine the effect of increasing the power generation of the PVT panel, owing to the effect of the surface temperature drop in the air-based PVT system. The maximum power of the PVT panel that allowed air to pass through the panel increased by $21.9 \mathrm{~W}$ (Figure 10). However, it is difficult to analyze the variation in the amount of electricity generated by the change in insolation quantitatively. Therefore, in this study, the relationship between insolation and power generation was analyzed for each PV panel and PVT panel. For the correlation between solar radiation and power generation (Figure 11), the coefficient of PVT increased by approximately $6.8 \%$ compared to that of PV during the measurement period (PVT: 0.2462, PV: 0.2585). The increase in power generation due to PVT application during the measurement 
period is about $268.0 \mathrm{Wh}$. The power consumption of the fan used for air emission during power generation is $190.8 \mathrm{Wh}$. Although the increase in power generation due to the PVT application was somewhat higher than the power consumption of the fan, this is a result of the summer when the outdoor temperature is high, and it is thought that the increase in the amount of power generation will increase as the outdoor temperature in winter decreases. In addition, in order to increase the effect of applying the PVT system, it is necessary to additionally examine the appropriate capacity and control method of the exhaust fan.

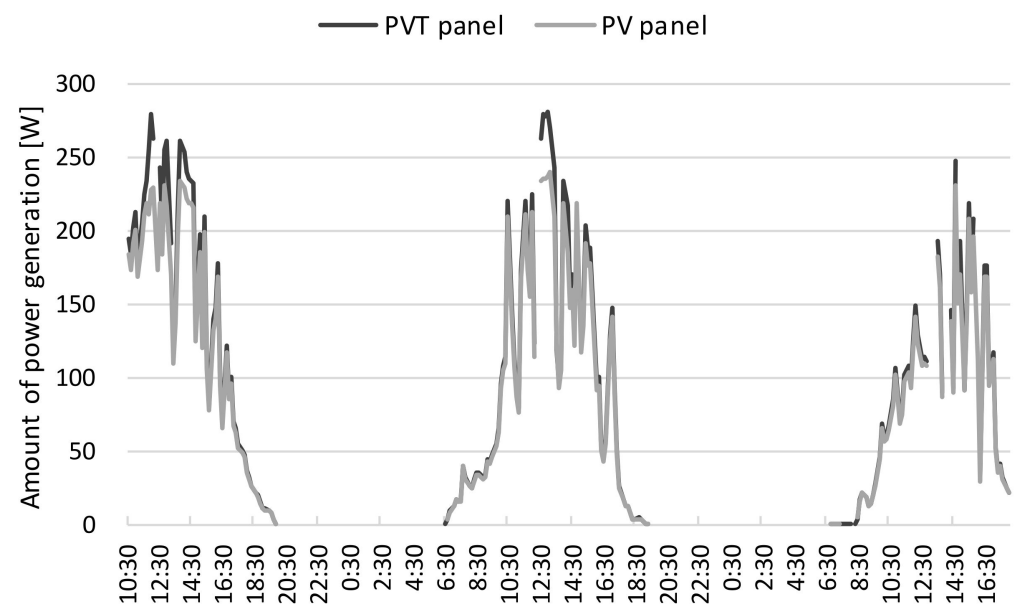

Figure 10. Variations in power generation of photovoltaic (PV) and PVT panels.

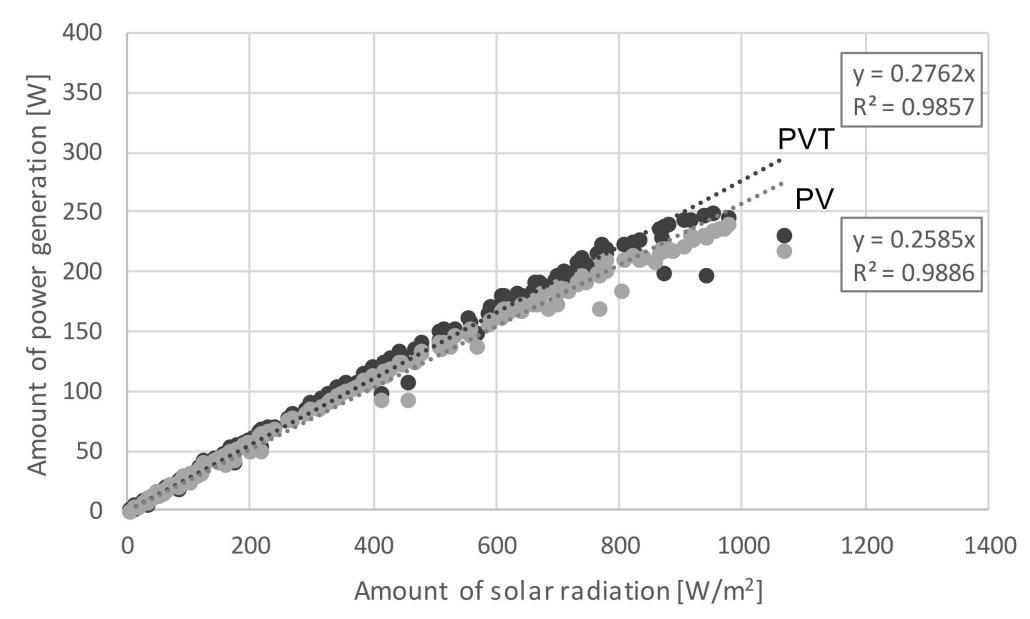

Figure 11. Relationship between insolation and power generation.

The power generation efficiency values of the PV and PVT panels were calculated based on the measured insolation and power generation (Figure 12). The power generation efficiency values of the PVT and PV panels were $22.9 \%$ and $20.8 \%$, respectively. This results in an approximately $10.1 \%$ increase in the power generation efficiency, owing to the airflow under the panel. In addition, the solar heat of the PVT was collected, owing to an increase in the air temperature, which was approximately $46.6 \%$. Therefore, the solar energy utilization efficiency of the PVT was $69.5 \%$ (Figure 13), which was significantly higher than that of the PV $(20.8 \%)$. The air heated by the PVT system can be directly introduced into the room in winter and used as heating. In addition, under a condition in which an indoor heating load does not occur, it can be used for hot water supply through heat exchange with water, and can be used for regeneration of desiccant for indoor dehumidification. Further research is needed on system construction and control methods for the proper use of heated air. 


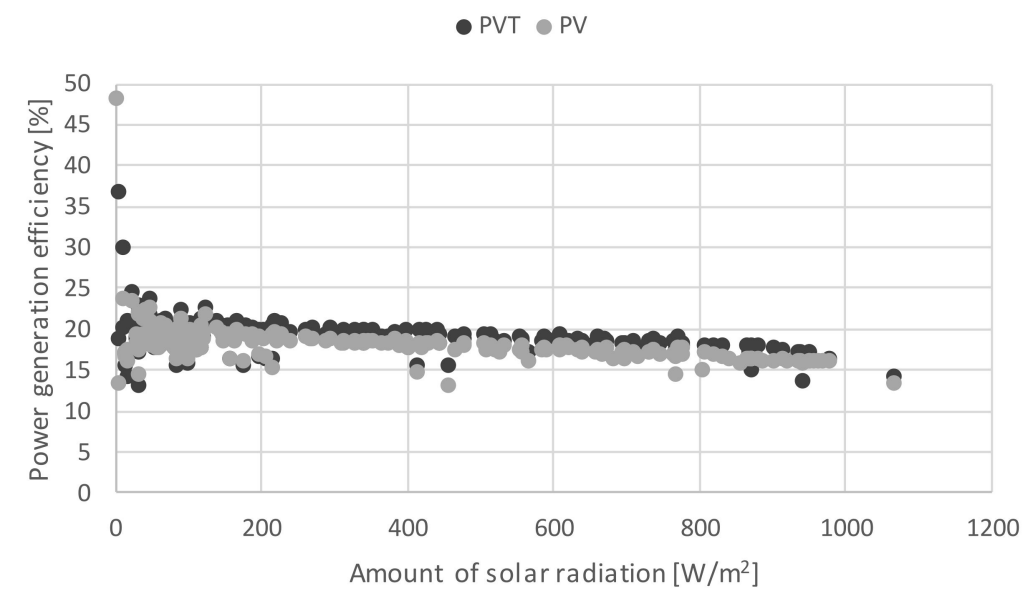

Figure 12. Power generation efficiency of PVT and PV panels.

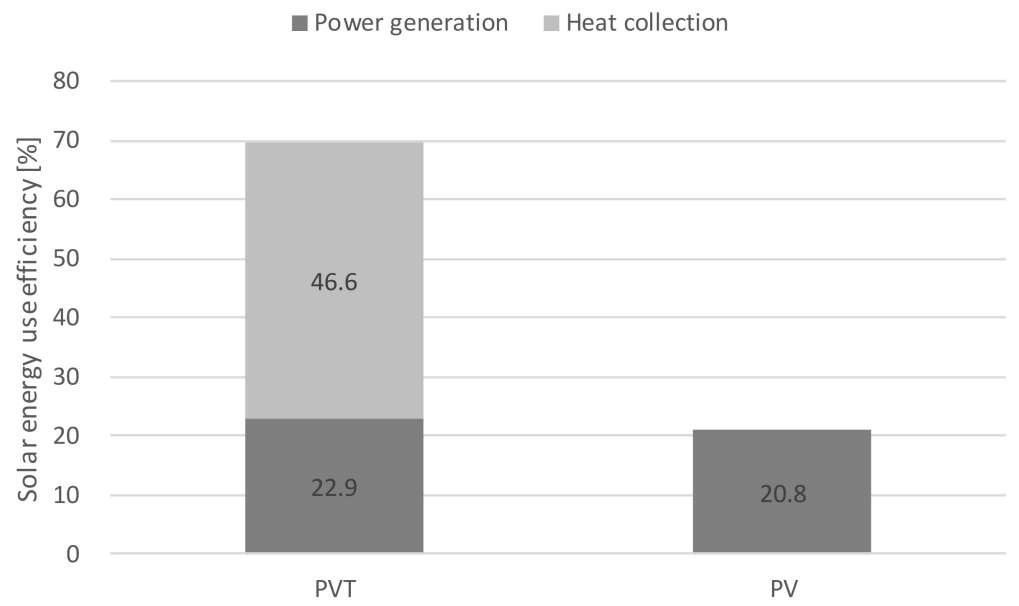

Figure 13. Solar energy utilization efficiency of PVT and PV panels.

\section{Conclusions}

In this study, the application of solar energy, which is the most usable renewable energy source in buildings and easy to maintain, was reviewed. In particular, the power generation and heat collection performance of the PVT system, a combination of the existing solar power generation and solar heat collection systems, were determined through measurements.

The target system of this study was an air-based PVT system. The system decreased the surface temperature of the panel by passing the outside air through the lower part of the existing PV panel, increasing the solar power generation efficiency by approximately $10.1 \%$. In addition, $46.6 \%$ of the thermal energy was obtained, owing to the increased temperature of the passing air. It is demonstrated that heated air can be utilized for heating and hot-water supply loads generated in buildings.

The experiments were conducted in summer when the outside air temperature was relatively high; hence, the effect of the panel temperature decrease attributed to air passage may be less significant in other seasons. Therefore, further research on the variations in the cooling effect and power generation efficiency of the panel with the outdoor temperature is required. In addition, it is necessary to review the method for controlling the required temperature by controlling the fan rotation speed to utilize the elevated air temperature in the building effectively. Furthermore, the utilization method and effect on the building should be investigated. 
Author Contributions: Conceptualization, Y.C.; methodology, Y.C. and H.B.K.; validation, H.B.K.; writing-original draft preparation, Y.C. All authors have read and agreed to the published version of the manuscript.

Funding: This work was supported by the National Research Foundation of Korea (NRF) grant funded by the Korea government (MSIT) (No. 2020-0298).

Institutional Review Board Statement: Not applicable.

Informed Consent Statement: Not applicable.

Data Availability Statement: Not applicable.

Conflicts of Interest: The authors declare no conflict of interest.

\section{References}

1. Hossain, M.S.; Saidur, R.; Fayaz, H.; Rahim, N.A.; Islam, M.R.; Ahamed, J.U.; Rahman, M.M. Review on Solar Water Heater Collector and Thermal Energy Performance of Circulating Pipe. Renew. Sustain. Energy Rev. 2011, 15, 3801-3812. [CrossRef]

2. $\quad$ Porras-Prieto, C.J.; Mazarrón, F.R.; de los Mozos, V.; García, J.L. Influence of Required Tank Water Temperature on the Energy Performance and Water Withdrawal Potential of a Solar Water Heating System Equipped with a Heat Pipe Evacuated Tube Collector. Sol. Energy 2014, 110, 365-377. [CrossRef]

3. Maraj, A.; Londo, A.; Gebremedhin, A.; Firat, C. Energy Performance Analysis of a Forced Circulation Solar Water Heating System Equipped with a Heat Pipe Evacuated Tube Collector under the Mediterranean Climate Conditions. Renew. Energy 2019, 140, 874-883. [CrossRef]

4. Hassan, H. Comparing the Performance of Passive and Active Double and Single Slope Solar Stills Incorporated with Parabolic Trough Collector via Energy, Exergy and Productivity. Renew. Energy 2019, 148, 437-450. [CrossRef]

5. Abuşka, M.; Şevik, S. Energy, Exergy, Economic and Environmental (4E) Analyses of Flat-Plate and V-Groove Solar Air Collectors Based on Aluminium and Copper. Sol. Energy 2017, 158, 259-277. [CrossRef]

6. Choi, Y.; Takase, K.; Mae, M. System Performance of a Residential Building Using the Air-Based Solar Heating System. Sol. Energy 2018, 171, 47-63. [CrossRef]

7. Beausoleil-Morrison, I.; Kemery, B.; Wills, A.D.; Meister, C. Design and Simulated Performance of a Solar-Thermal System Employing Seasonal Storage for Providing the Majority of Space Heating and Domestic Hot Water Heating Needs to a SingleFamily House in a Cold Climate. Sol. Energy 2019, 191, 57-69. [CrossRef]

8. Attar, I.; Farhat, A. Efficiency Evaluation of a Solar Water Heating System Applied to the Greenhouse Climate. Sol. Energy 2015, 119, 212-224. [CrossRef]

9. Martinopoulos, G.; Tsalikis, G. Diffusion and Adoption of Solar Energy Conversion Systems e The Case of Greece. Energy 2020, 144, 800-807. [CrossRef]

10. Martinopoulos, G.; Serasidou, A.; Antoniadou, P. Building Integrated Shading and Building Applied Photovoltaic System Assessment in the Energy Performance and Thermal Comfort of Office Buildings. Sustainability 2018, 10, 4670. [CrossRef]

11. Ravyts, S.; Dalla Vecchia, M.; Van den Broeck, G.; Driesen, J. Review on Building-Integrated Photovoltaics Electrical System Requirements and Module-Integrated Converter Recommendations. Energies 2019, 12, 1532. [CrossRef]

12. Lämmle, M.; Oliva, A.; Hermann, M.; Kramer, K.; Kramer, W. PVT Collector Technologies in Solar Thermal Systems: A Systematic Assessment of Electrical and Thermal Yields with the Novel Characteristic Temperature Approach. Sol. Energy 2017, 155, 867-879. [CrossRef]

13. Yu, G.; Yang, H.; Yan, Z.; Kyeredey, M. A Review of Designs and Performance of Façade-Based Building Integrated PhotovoltaicThermal ( BIPVT ) Systems. Appl. Therm. Eng. 2021, 182, 116081. [CrossRef]

14. Zarei, A.; Liravi, M.; Babaie, M.; Ghodrat, M. A Novel, Eco-Friendly Combined Solar Cooling and Heating System, Powered by Hybrid Photovoltaic Thermal (PVT) Collector for Domestic Application. Energy Convers. Manag. 2020, 222, 113198. [CrossRef]

15. Syakirah, N.; Fudholi, A.; Bakhtyar, B.; Hoy, C.; Ibrahim, A.; Ha, M.; Mat, S.; Sopian, K. Energy Economic Analysis of Photovoltaic-Thermal-Thermoelectric (PVT-TE) Air Collectors. Renew. Sustain. Energy Rev. 2018, 92, 187-197. [CrossRef]

16. Numan, A.; Kaya, F. Effect on the Exergy of the PVT System of Fi Ns Added to an Air-Cooled Channel: A Study on Temperature and Air Velocity with ANSYS Fluent. Sol. Energy 2019, 184, 561-569. [CrossRef]

17. Wajs, J.; Golabek, A.; Bochniak, R.; Mikielewicz, D. Air-Cooled Photovoltaic Roof Tile as an Example of the BIPVT System e An Experimental Study on the Energy and Exergy Performance. Energy 2020, 197, 117255. [CrossRef]

18. Singh, G.; Kumar, S.; Tiwari, G.N. Design, Fabrication and Performance Evaluation of a Hybrid Photovoltaic Thermal ( PVT ) Double Slope Active Solar Still. DES 2011, 277, 399-406. [CrossRef]

19. Lateef, A.; Misha, S.; Tamaldin, N.; Rosli, M.A.M.; Sachit, A. Case Studies in Thermal Engineering Theoretical Study and Indoor Experimental Validation of Performance of the New Photovoltaic Thermal Solar Collector ( PVT ) Based Water System. Case Stud. Therm. Eng. 2020, 18, 100595. [CrossRef]

20. Vittorini, D.; Castellucci, N.; Cipollone, R. Heat Recovery Potential and Electrical Performances In- Fi Eld Investigation on a Hybrid PVT Module. Appl. Energy 2017, 205, 44-56. [CrossRef] 
21. Sakellariou, E.I.; Wright, A.J.; Axaopoulos, P.; Oyinlola, M.A. PVT Based Solar Assisted Ground Source Heat Pump System: Modelling Approach and Sensitivity Analyses. Sol. Energy 2019, 193, 37-50. [CrossRef]

22. Brottier, L.; Bennacer, R. Thermal Performance Analysis of 28 PVT Solar Domestic Hot Water Installations in Western Europe. Renew. Energy 2020, 160, 196-210. [CrossRef]

23. Hengel, F.; Heschl, C.; Inschlag, F.; Klanatsky, P. International Journal of Thermo Fl Uids System Ef Fi Ciency of Pvt CollectorDriven Heat Pumps. Int. J. Thermofluids 2020, 5-6, 100034. [CrossRef]

24. Ramos, A.; Chatzopoulou, M.A.; Guarracino, I.; Freeman, J.; Markides, C.N. Hybrid Photovoltaic-Thermal Solar Systems for Combined Heating, Cooling and Power Provision in the Urban Environment. Energy Convers. Manag. 2017, 150, 838-850. [CrossRef]

25. Calise, F.; Dentice, M.; Vanoli, L. Design and Dynamic Simulation of a Novel Solar Trigeneration System Based on Hybrid Photovoltaic/Thermal Collectors (PVT). Energy Convers. Manag. 2012, 60, 214-225. [CrossRef]

26. Fayaz, H.; Rahim, N.A.; Hasanuzzaman, M.; Nasrin, R.; Rivai, A. Numerical and Experimental Investigation of the Effect of Operating Conditions on Performance of PVT and PVT-PCM. Renew. Energy 2019, 143, 827-841. [CrossRef]

27. Penaka, S.R.; Saini, P.K.; Zhang, X. Digital Mapping of Techno-Economic Performance of a Water-Based Solar Photovoltaic/Thermal (PVT) System for Buildings over Large Geographical Cities. Buildings 2020, 10, 148. [CrossRef] 